\title{
Evaluation of Soil Engineering Characteristics in Jalalpur Region, Pakistan
}

\author{
KHAWAJAADEEL TARIQ*, MUHAMMAD MOEEN SOHARWARDY**, AND NADEEMAHMED TABESSUM***
}

RECEIVED ON 14.03.2018 ACCEPTED ON 17.08.2018

\begin{abstract}
This study deals with the evaluation of soil engineering characteristic along the proposed route of Jalalpur irrigation project. The proposed JIP (Jalalpur Irrigation Project) is located along the right bank of Jhelum River in Tehsil PDK (Pind Dadan Khan) and Tehsil Khushab of District Khushab. JIP is funded by ADB (Asian Development Bank). The JIP will enhance crop production in Tehsil PDKand Khushab. Famers will be benefited through JIP as they will get regular supply of water through canal. It will also create job opportunities for local people and will lead to the prosperity of the Project area.

Detailed soil investigation along proposed route was carried out by M/S GEOBAND. Straight rotary method of drilling was used. The recovered soil samples and water samples were tested in laboratories. The detailed engineering analysis was performed and soil parameters along with bearing capacities are suggested. Results have indicated variations in SPT values along the proposed route. The top layer of soil along proposed route is mostly Silty Clay with variation along the depth. The proposed bearing capacity for shallow foundation is $1.25 \mathrm{ton} / \mathrm{ft}^{2}\left(120 \mathrm{kN} / \mathrm{m}^{2}\right)$ at depth of $5 \mathrm{ft}(1.5 \mathrm{~m})$ beneath footing, and for bored piles having diameter of $2.5 \mathrm{ft}(0.76 \mathrm{~m})$ at a depth of $50 \mathrm{ft}(15 \mathrm{~m})$ is recommended as 70 ton $(685 \mathrm{kN})$. The results presented in this study will be helpful in deciding the detailed foundation design of the engineering structures along the proposed route of JIP.
\end{abstract}

Key Words: Soil Investigation, Drilling, Foundation, Irrigation, Bearing Capacities.

\section{INTRODUCTION}

$\mathrm{W}$

ater Resource Institute has ranked Pakistan among Extremely High Water Stressed countries (Ratio of Withdrawal to Supply)

[1]. There is an urgent need for the sustainable development of water bodies in Pakistan. The proposed JIP is located along the right bank of Jhelum River in Tehsil PDK and Tehsil Khushab of District Khushab. It is located between longitude from $72^{\circ}-20^{\prime \prime}$ to $73^{\circ}-31$ (east) and latitude from $32^{\circ}-25$ to $32^{\circ}-43$ (north) along right bank of River Jhelum in Punjab, Pakistan [2]. The location of the project area is shown in Fig. 1.

The JIP project comprises of a main canal of $110 \mathrm{~km}$ that will off take from right bank of Rasul Barrage. It will then

Authors E-Mail: (khawajaadeel@hotmail.com. engr_moeen@yahoo.com, geobandwm@gmail.com) Department of Civil Engineering, Chenab College of Engineering and Technology Gujranwala, Pakistan.

** $\quad$ National Engineering Services, Pakistan

** GEOBAND, Pakistan

This is an open access article published by Mehran University Research Journal of Engineering and Technology, Jamshoro under the CC by 4.0 International License. 
cross right bank of Jhelum river. The canal will irrigate a command area of about 67,987 hectares. The command area of JIP is in the form of a long strip of land bounded by the Salt Range Hills on northern side and right bank of the Jhelum River on southern side. The distribution system of about $176 \mathrm{~km}$ comprising of distributaries and minors extends up to the right bank of Jhelum River. The JIP will create new non-perennial irrigation services for enhanced agricultural production on 79,750 ha in PDK and Khushab districts. It will also increase kharif crop intensity by $50 \%$, improve crop yield and reduce land degradation. The JIP will directly benefit over 200,000 rural people; mostly poor. The construction of proposed irrigation scheme also cause the removal of more than 300 main residential and commercial structures permanently and displacement of small business structures of the owners, removal of 9767 trees, crop losses, a few community facilities and pubic structure [3]. The proposed alignment route is shown in Fig. 1.

Smaller Cholistan irrigation project lies toward east of Sutlej river and is contiguous to the commands of Eastern
Sadiqia and Bahawal Canal Systems. It has a gross area of about 0.697 million acres and lies in Bahawalpur district. The whole area is a waste crown land without irrigation water either from surface or ground water source, whereas the land has good potential for irrigated agriculture similar to lands adjoining the command areas of Eastern Sadiqia and Bahawal Canal Systems. The abandoned area of Hakra Branch is also a part of the Project Area.

The purpose of the study is to determine the sub-surface conditions, physical, mechanical and chemical properties of the investigated ground, and to recommend safe bearing capacities of the ground.

\section{MATERIALS AND METHOD}

The characteristics of soils were investigated by drilling boreholes along proposed alignment and in adjacent areas. Standard penetration test along with permeability test was also performed in drilled holes. The samples collected from site investigation were tested in Laboratory.

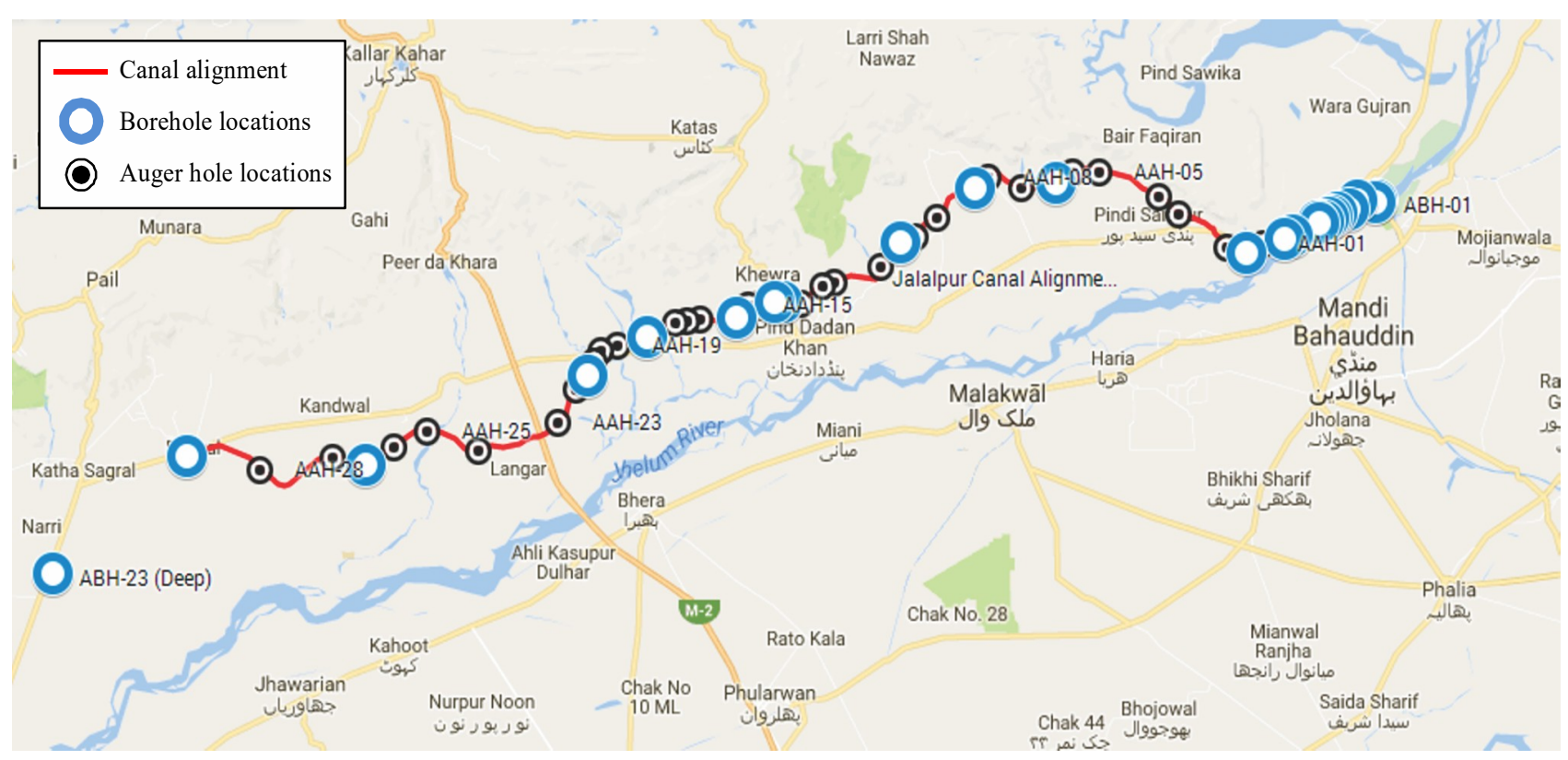

FIG. 1. PROJECT LAYOUT SHOWING BOREHOLE (ABH) AND AUGER HOLE (AAH) LOCATIONS

Mehran University Research Journal of Engineering \& Technology, Volume 38, No. 3, July, 2019 [p-ISSN: 0254-7821, e-ISSN: 2413-7219] 


\subsection{Field Investigation}

\subsubsection{Drilling of boreholes}

The exploratory boreholes were drilled in the project area by M/S GEOBAND. Straight rotary method of drilling was employed with bentonite slurry as drilling fluid. In total, 23 boreholes $(\mathrm{ABH})$ were drilled along the route (Table 1). Two (2) boreholes were also drilled to a depth of 200 feet $(60 \mathrm{~m})$. In addition to that, auger holes were also drilled (AAH).

TABLE 1. DETAILS OF SAMPLES COLLECTED DURING DRILLING

\begin{tabular}{|c|c|c|c|}
\hline \multicolumn{2}{|c|}{ Borehole No. } & \multicolumn{2}{|c|}{ No. Samples with Depth } \\
\hline No. & Drilling Depthft (m) & Undisturbed & Disturbed \\
\hline ABH-01 & $50(15)$ & 2 & 2 \\
\hline ABH-02 & $50(15)$ & 1 & 1 \\
\hline ABH-03 & $36(11)$ & 3 & - \\
\hline ABH-04 & $36(11)$ & 1 & - \\
\hline ABH-05 & $36(11)$ & 3 & 1 \\
\hline ABH-06 & $36(11)$ & 3 & 1 \\
\hline ABH-07 & $36(11)$ & 3 & - \\
\hline ABH-08 & $36(11)$ & 4 & 1 \\
\hline ABH-09 & $36(11)$ & 3 & - \\
\hline ABH-09A & $36(11)$ & 1 & 2 \\
\hline ABH-10 & $36(11)$ & 3 & 0 \\
\hline ABH-11 & $36(11)$ & 1 & - \\
\hline ABH-12 & $36(11)$ & 1 & 2 \\
\hline ABH-13 & $80(24)$ & 7 & 1 \\
\hline ABH-14 & $36(11)$ & 4 & 2 \\
\hline ABH-15 & $70(21)$ & 4 & - \\
\hline ABH-16 & $40(12)$ & 2 & 2 \\
\hline ABH-17 & $38(11)$ & 2 & 1 \\
\hline ABH-18 & $77(23.5)$ & 2 & 2 \\
\hline ABH-19 & $36(11)$ & 2 & 1 \\
\hline ABH-19A & $41(12.5)$ & 4 & 1 \\
\hline ABH-20 (Deep) & $200(60)$ & 3 & 0 \\
\hline $\mathrm{ABH}-20 \mathrm{~A}$ & $36(11)$ & 3 & - \\
\hline ABH-21 (Deep) & $200(60)$ & 3 & 2 \\
\hline ABH-22 & $51(15)$ & 3 & 1 \\
\hline ABH-23 & $85(26)$ & 3 & - \\
\hline Total & $1488(435)$ & 71 & 23 \\
\hline
\end{tabular}




\subsubsection{Collection of Soil and Water Samples}

UDS (Undisturbed), DS (Disturbed) and Split Spoon samples were obtained from the boreholes. DS samples using a Split barrel tube sampler were obtained where SPT was performed in the soil.

The samples recovered were immediately examined, described, classified, identified, wrapped in water proof plastic sheets, placed in proper sequence in heavy duty wooden boxes and taken to laboratory for testing.

All the samples were protected against the weather condition, until they had been transported to the laboratory for testing. Care was taken during handling, packing, transportation and storing of samples to protect them against all structural and moisture alterations. Details of samples collected during drilling of boreholes are given in Table 1. The UDS and water samples are generally collected at an average depth of about $5 \mathrm{~m}$.

\subsubsection{Standard Penetration Tests}

SPT (Standard Penetration Tests) were performed in all the boreholes at a general depth interval of $1.0 \mathrm{~m}$. The SPT consists of driving a Standard $50 \mathrm{~mm}$ outside diameter split spoon sampler into soil at the bottom of boreholes, using repeated blows of a $63.5 \mathrm{~kg}(623 \mathrm{~N})$ hammer falling through $760 \mathrm{~mm}$. The SPT $\mathrm{N}$ values are the number of blows required to achieve a penetration of $300 \mathrm{~mm}$, after an initial seating at the depths of the tests [4]. Appropriate description of the retrieved samples was noted on the borehole logs. The details are presented in Table 1.

\subsubsection{Permeability Tests}

Total forty-four (44) constant head permeability tests were performed in boreholes.

\subsubsection{Laboratory Testing}

The samples recovered from boreholes were tested in Laboratory. Grain size, chemical analysis, soil property, moisture content and direct shear tests were performed.

\section{RESULTS AND DISCUSSIONS}

\subsection{Field Investigation}

Sub-surface stratification along the alignment of proposed canal generally consists of layers of Silty Clay/ Clayey Silt and Silty Sand with presence of Sandy Gravel in few boreholes. The top layer mostly consists of Silty Sand /Silty Clay and Sand at greater depth.

\subsubsection{Field and Corrected SPT $\mathrm{N}_{60}$ Values}

Graphical presentations of variation of SPT blow counts both for field and corrected " $\mathrm{N}_{60}$ " [5] values along the proposed Canal alignment for $\mathrm{ABH}-10$ and $\mathrm{ABH}-20$ are shown in Fig. 2(a-b). The field result shows that SPT $\mathrm{N}_{60}$ values generally lies in-between 10 and 20 along canal alignment closer to the ground; with increasing trend along depth. The profile of ABH-16 is shown in Fig. 3.

Figure 2: SPT variation along depth for (a) $\mathrm{ABH}-$ 10 and (b) ABH-20

\subsubsection{Field Permeability Tests}

Permeability test results have indicated variation in permeability values. The minimum and maximum values observed in borehole are of order of $10^{-3}$ and $10^{-6} \mathrm{~cm} / \mathrm{s}$ respectively.

\subsubsection{Shear Strength Parameters based on SPT N Value}

SPT " $N$ " field values have been corrected to $\mathrm{N}_{60}$ with respect to overburden pressures and energy transfer. 
Further these corrected $\mathrm{N}_{60}$-values have been used to estimate the Unconfined Compressive Strength of Silty

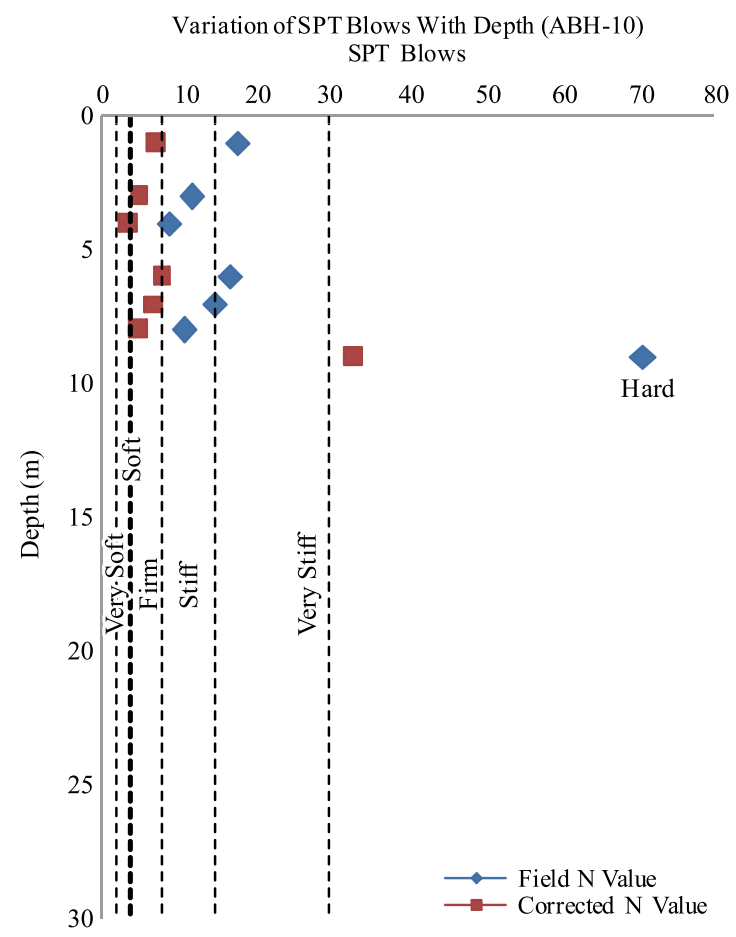

(a) $\mathrm{ABH}-10$

Variation of SPT Blows With Depth (ABH-20) SPT Blows

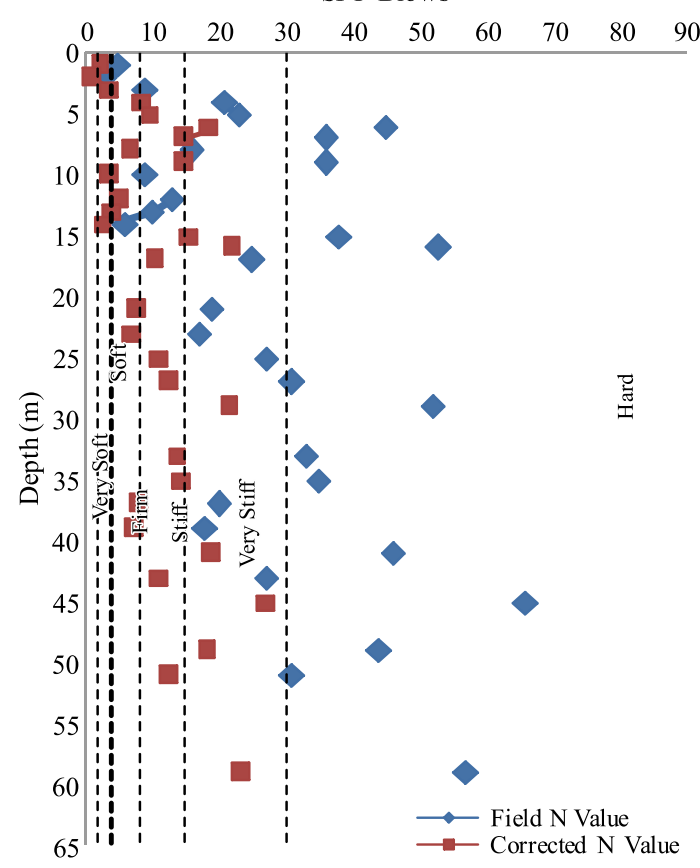

(b) $A B H-20$

FIG. 2. SPT VARIATION ALONG DEPTH
Clay/Clayey Silt soil and effective angle of internal friction for the sand.

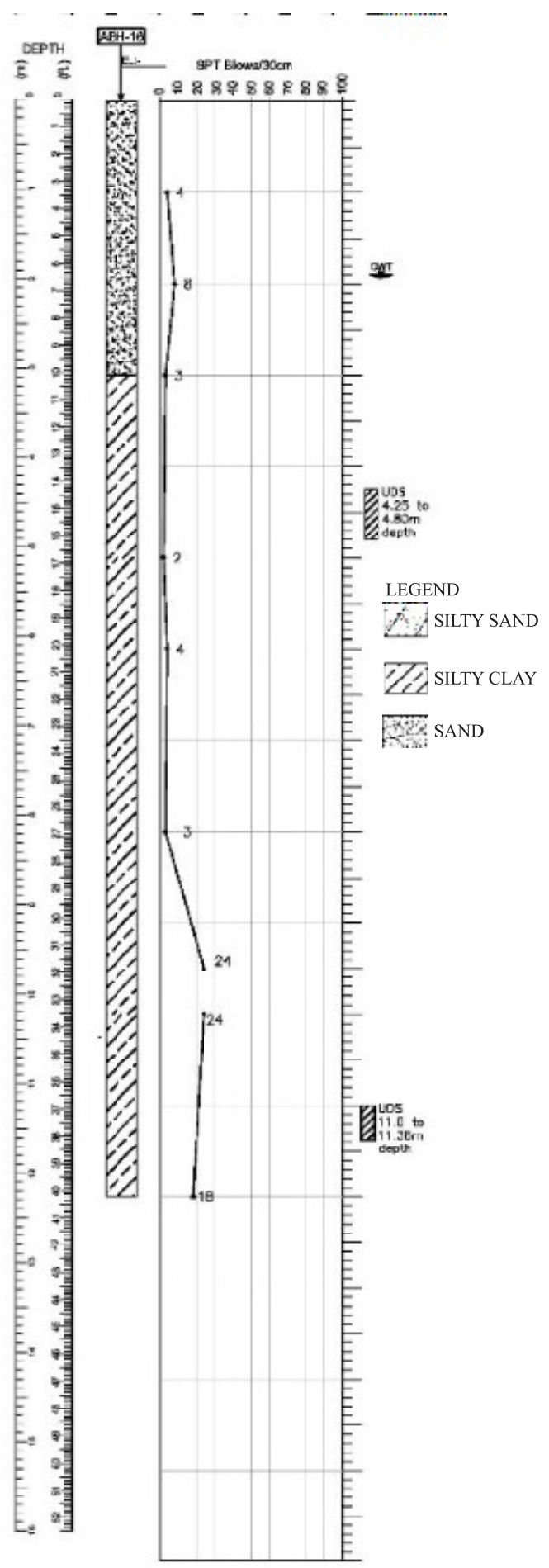

FIG. 3. PROFILE OF ABH-16

Mehran University Research Journal of Engineering \& Technology, Volume 38, No. 3, July, 2019 [p-ISSN: 0254-7821, e-ISSN: 2413-7219] 
Undrained Shear Strength $\left(\mathrm{C}_{\mathrm{u}}\right)$ and Unconfined Compressive Strength $\left(\mathrm{q}_{\mathrm{u}}\right)$ of Silty Clay/Clayey Silt has been estimated by using the empirical relationship [6]. Similarly, effective angle of internal friction $(\phi)$ has been estimated [7] and average along depth is given in Table 2, which shows that effective angle of internal friction, generally varies from 30-36 degrees.

TABLE 2. AVERAGE SPT $N, N_{60}, \Phi, C_{U}$ AND $q_{u}$ ALONG ALIGNMENT

\begin{tabular}{|c|c|c|c|c|c|c|}
\hline \multirow{2}{*}{ Borehole } & \multicolumn{4}{|c|}{ Average Along Depth } & \multirow{2}{*}{$\frac{\mathrm{C}_{\mathrm{u}} * * *}{\mathrm{kN} / \mathrm{m}^{2}}$} & \multirow{2}{*}{$\frac{\mathrm{q}_{\mathrm{u}}=\mathrm{C}_{\mathrm{u}} \times 2}{\mathrm{kN} / \mathrm{m}^{2}}$} \\
\hline & SPT N & $\mathrm{N}_{60}^{*}$ & $\phi * *$ & $\phi$ (laboratory) & & \\
\hline ABH-01 & 20 & 10 & 34.1 & 33.9 & - & - \\
\hline ABH-02 & 20 & 10 & 33.2 & 33.9 & - & - \\
\hline ABH-03 & 38 & 16 & 35.5 & 35.0 & - & - \\
\hline ABH-04 & 46 & 21 & 35.9 & 34.1 & - & - \\
\hline ABH-05 & 44 & 19 & 30.1 & 34.8 & - & - \\
\hline ABH-06 & 76 & 31 & 30.0 & 31 & 138 & 276 \\
\hline ABH-07 & 73 & 36 & 31.0 & 34.9 & 158 & 317 \\
\hline ABH-08 & 53 & 22 & 35.7 & - & 96 & 192 \\
\hline ABH-09 & 42 & 17 & 36.9 & 35.7 & - & - \\
\hline ABH-09A & 84 & 35 & 30.0 & - & - & - \\
\hline ABH-10 & 22 & 10 & 32.6 & 34.3 & - & - \\
\hline ABH-11 & 32 & 13 & 36.3 & 33.7 & - & - \\
\hline ABH-12 & 29 & 12 & 34.6 & - & - & - \\
\hline ABH-13 & 14 & 7 & 30.7 & 33.5 & 32 & 65 \\
\hline ABH-14 & 13 & 5 & 31.1 & - & 24 & 48 \\
\hline $\mathrm{ABH}-15$ & 14 & 7 & 29.0 & - & 30 & 61 \\
\hline ABH-16 & 8 & 4 & 30.0 & 35 & 16 & 33 \\
\hline ABH-17 & 10 & 4 & 31.2 & - & 18 & 35 \\
\hline ABH-18 & 13 & 7 & 31.5 & 33.8 & 29 & 59 \\
\hline ABH-19 & 9 & 4 & 30.7 & - & 17 & 33 \\
\hline ABH-19A & 13 & 5 & 30.0 & - & 24 & 48 \\
\hline ABH-20 & 19 & 13 & 31.8 & 33.4 & 55 & 110 \\
\hline ABH-21 & 9 & 10 & 31.4 & 33.1 & 45 & 90 \\
\hline ABH-22 & 6 & 3 & 30.9 & - & 11 & 22 \\
\hline
\end{tabular}




\subsubsection{Analysis of laboratory Testing}

Grain analysis performed on recovered soil samples. Soil samples are classified as SP-SM, SW-SM, whereas most of the sample classified as SM and CL/ML [8]. Most samples have Plasticity Index between 10 and 20; therefore, there is medium swelling potential capacity of soil [9]. The values of specific gravity were found in the range of 2.07-2.79. The values of bulk density were found in the range of $19-21 \mathrm{kN} / \mathrm{m}^{3}$. The natural moisture content varies from 4.9-25.87\%. The Unconfined Compressive Strength $(\mathrm{kPa})$ was between $17.7-420 \mathrm{kPa}$ and Angle of Internal friction was between $31-36^{\circ}$.

Based on laboratory test results, following soil parameters are recommended:

For Silty Sand

$\gamma_{\text {bulk }}=18 \mathrm{kN} / \mathrm{m}^{3}, \phi=30$ degrees, $\mathrm{G}_{\mathrm{s}}=2.4$

For Clayey Silty / Silty Clay

$\gamma_{\text {bulk }}=18 \mathrm{kN} / \mathrm{m}^{3}, \phi=28$ degrees, $\mathrm{C}=15 \mathrm{kPa}, \mathrm{G}_{\mathrm{s}}=2.4$

Due to low concentration of Sulphate and Chloride Content in soil samples of some areas, the use of OPC (Ordinary Port Land Cement) is recommended.

\subsubsection{Bearing Capacity Curves for Foundation}

\subsubsection{Geotechnical Foundation Design Criteria}

Following criteria is opted for estimation of bearing capacities:

(i) Foundation should be safe against shear failure of the supporting ground. A factor of safety of 3.0 is adopted for this purpose.

(ii) Foundation should not settle excessively under the service loads. A limit of $25 \mathrm{~mm}$ has been put on the total settlement of individual foundations.

\subsubsection{Bearing Capacity Curves for Shallow Foundation Based on SPT $\mathbf{N}_{60}$}

The summary of the average SPT N, $\mathrm{N}_{60}$ and $\phi$ along depth is given in Table 2 for boreholes along canal alignment. Variation is observed in average SPT $\mathrm{N}_{60}$ value along depth. Minimum 3 and Maximum 36 SPT $_{60}$ is observed. The angle of internal friction from limited laboratory tests are also compared with estimated angle of internal friction from field SPT values. There is a good agreement between empirically and laboratory estimated angle of internal friction values with few exceptions. The bearing capacity curve has been developed for Silty Sand considering depth of foundation as $1.5 \mathrm{~m}$ (Fig. 4) using Meyerhof's equations [10]. At this depth, the minimum and maximum SPT $\mathrm{N}_{60}$ values among all boreholes are 1 and 17, with mostly values falling below 5 . Therefore, SPT $\mathrm{N}_{60}$ as 4 and $\phi$ as $30^{\circ}$ is selected for bearing capacity curve [11]. Keeping in view variation in SPT $\mathrm{N}_{60}$ values, it is highly recommended to use SPT $\mathrm{N}_{60}$ values of a particular borehole in the vicinity of the proposed structure. The bearing capacity of 1.25 ton $/ \mathrm{ft}^{2}\left(120 \mathrm{kN} / \mathrm{m}^{2}\right)$ is recommended.

\subsubsection{Bearing Load Curves for Deep Foundation (Bored Pile)}

The bearing capacity of the pile for bored condition ( $\mathrm{RC}$ piles under compression) has been determined (Pile Dia $2.5 \mathrm{ft}(0.76 \mathrm{~m})$ and $3.5 \mathrm{ft}(1 \mathrm{~m}))$ using modified version of Terzaghi's equation/NAVFAC DM 7.2 [12] for medium dense sand condition (Fig. 5(a-b)). The depth of water is considered as $5 \mathrm{ft}(1.5 \mathrm{~m})$. Factor of safety adopted for the allowable bearing load is $3, \gamma=18 \mathrm{kN} / \mathrm{m}^{3}, \mathrm{~N}_{\mathrm{q}}=10, \mathrm{~N}_{\mathrm{q}}{ }^{*}=55$, $\phi=30^{\circ}$ and $\gamma_{\mathrm{w}}=9.81 \mathrm{kN} / \mathrm{m}^{3}$. Skin resistance is considered as constant after $15 \mathrm{D}$ (For medium dense sand). Bearing capacity is the summation of skin and end point resistance. In addition to that, bearing capacity curves have been 


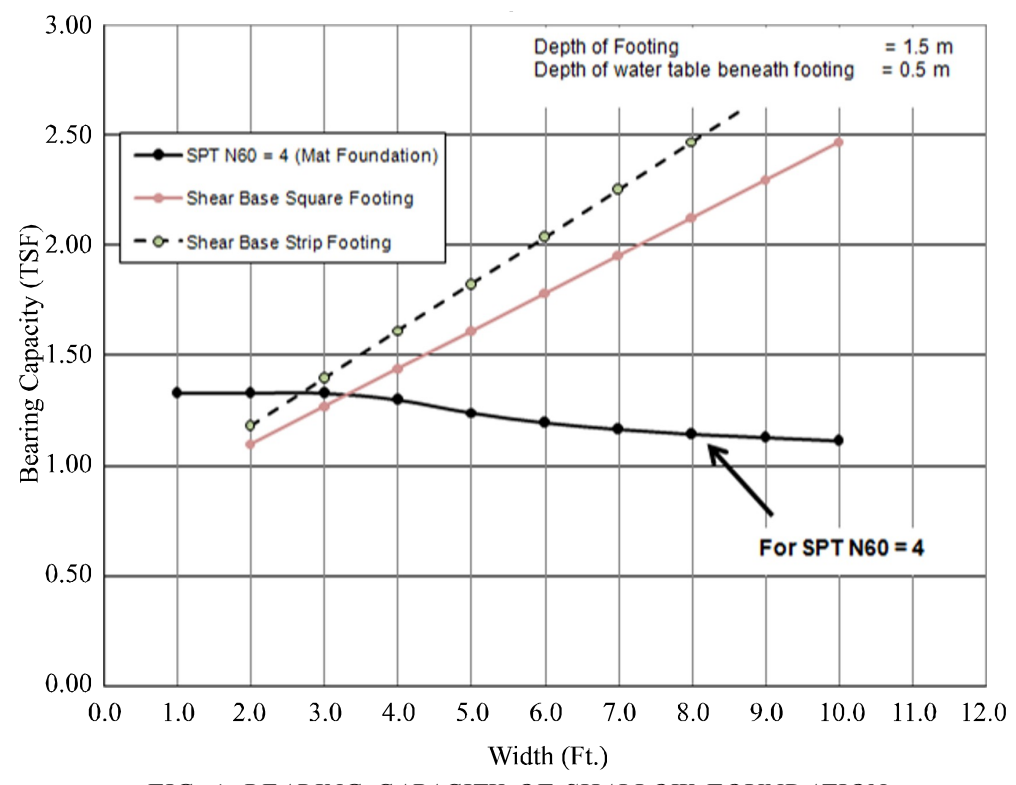

FIG. 4. BEARING CAPACITY OF SHALLOW FOUNDATION
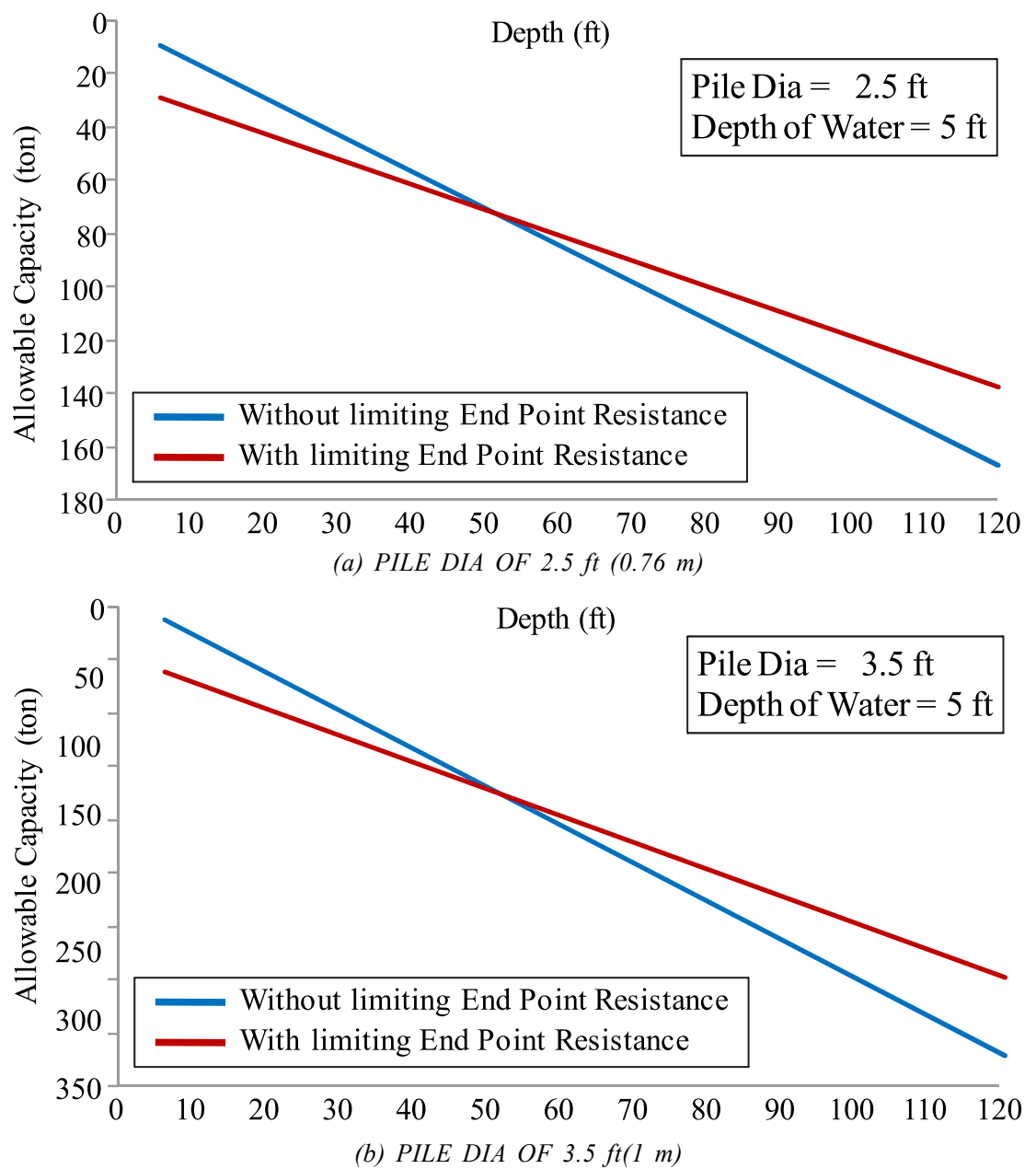

FIG. 5. PILE CAPACITY FOR BORED CONDITION 
developed considering recommendation of Meyerhoff about limiting end point resistance. Following equations are used to estimate bearing capacity of deep foundation [12]:

$S=K \times \sigma_{v}^{\prime} \times \tan \delta \times A_{p}$

$q_{p}=\left(0.5 p_{a} N_{q}^{*} \tan \phi^{\prime}\right) A_{p}$

Where $S$ is skin friction of the pile, $q_{p}$ is limiting point resistance, $\mathrm{K}$ is lateral earth pressure coefficient, $\tan \delta$ is friction angle between pile and soil, $\sigma_{\mathrm{v}}$ is effective stress at the midpoint of the pile, $\mathrm{p}_{\mathrm{a}}$ is atmospheric pressure (100 $\left.\mathrm{kN} / \mathrm{m}^{2}\right), \mathrm{N}_{\mathrm{q}}^{*}$ is bearing factor coefficient, $\phi^{\prime}$ is effective angle of internal friction, and $\mathrm{A}_{\mathrm{p}}$ is perimeter areaof the pile.

\section{CONCLUSION}

In this study, ground condition along proposed route of JIP is investigated. The ground is assessed by laboratory testing and analytical techniques are used to estimate the safe bearing capacities. Following conclusion can be drawn from this study:

(i) The top layer mostly consists of Silty Clay along proposed canal alignment.

(ii) The bearing capacity curve for shallow and deep foundation has been developed. Considering the heterogeneity and complexity of the project area, it is highly recommended to use SPT $\mathrm{N}_{60}$ values or design parameters of a particular borehole in the vicinity of the proposed structure.

(iii) The samples recovered shows low to high swelling. Care must be taken with the use of cement type in proposed construction areas. (iv) The bearing capacity for shallow foundation at depth of $5 \mathrm{ft}(1.5 \mathrm{~m})$ beneath footing is recommended as 1.25 ton $/ \mathrm{ft}^{2}$

(v) The bearing capacity for bored piles having diameter of $2.5 \mathrm{ft}(0.76 \mathrm{~m})$ and $3.5 \mathrm{ft}(1 \mathrm{~m})$ at depth of about $50 \mathrm{ft}(15 \mathrm{~m})$ is recommended as 70 ton $(685 \mathrm{kN})$ and 130 ton $(1275 \mathrm{kN})$ respectively.

\section{ACKNOWLEDGMENT}

The authors wish to express his gratitude to NESPAK and M/S GEOBAND official, for their cooperation and valuable support in this work.

\section{REFERENCES}

[1] Water Resource Institute, World's 36 Most WaterStressed Countries http://www.wri.org/blog/2013/12/ world $\%$ E2\%80\%99s-36-most-water-stressed-countries)

[2] Term of Reference, Jalapur Irrigation Project, Government of Punjab, 2016

[3] Resettlement Plan, Jalapur Irrigation Project, Government of Punjab, 2017.

[4] ASTM D1586., "American Society for Testing and Materials. Standard Test Method for Standard Penetration Test (SPT) and Split-Barrel Sampling of Soils", 2011.

[5] Seed, H.B., Tokimatsu, K., Harder, L.F., and Chung, R.M., "Influence of SPT Procedures in Soil Liquefaction Resistance Evaluations", Journal of Geotechnical Engineering, ASCE, Volume 111, No. 12, pp. 1425-1445, 1985.

[6] Stroud, M.A., "The Standard Penetration Test in Insensitive Clays and Soft Rocks", Proceedings of European Symposium on Penetration Testing ESOPT, Stockholm, National Swedish Building Research, Volume 2, No. 2, pp.367-375, 1974. 
[7] Hatanaka, M., and Uchida, A., "Empirical Correlation between Penetration Resistance and Internal Friction Angle of Sandy Soil”, Journal Soils and Foundations, Volume 36, No. 4, pp. 1-10, 1996.

[8] ASTM D248., "Standard Practice for Classification of Soils for Engineering Purposes (Unified Soil Classification System)", American Society for Testing and Materials, West Conshohocken, Pennsylvania, USA, 2011.

[9] Bowles, J., "Foundation Analysis and Design", McGraw Hill, 5th Edition, New York, NY, USA, 1997.
[10] Meyerhof, G.G., "Penetration Test and Bearing Capacity of Cohesionless Soils", Journal of the Soil Mechanics and Foundation Division, ASCE, Volume 82, No. SM1, pp. 1-19, 1956.

[11] Murthy, V.N.S., "Geotechnical Engineering, Principle and Practices of Soil Mechanics and Foundation Engineering", Taylor and Francis Group, Chapter 12-14, CRC Press, 2002.

[12] NAVFAC DM7.2., "Foundations and Earth Structures", Naval Facilities Engineering Command,1984. 